\title{
RIGHT RENAL VEIN ELONGATION WITH THE INFERIOR VENA CAVA FOR CADAVERIC KIDNEY TRANSPLANTS. AN OLD NEGLECTED SURGICAL APPROACH
}

\author{
JOSE C. BAPTISTA-SILVA, JOSE O. MEDINA-PESTANA, MARCOS J.M. VERISSIMO, \\ MARCOS J. CASTRO, MARIS S. DEMUNER, MARCIO F. SIGNORELLI
}

\author{
Department of Surgery, Federal University of Sao Paulo, UNIFESP, Sao Paulo, Brazil
}

\begin{abstract}
Introduction: Short right renal vein is a frequent and well-known technical inconvenience that is commonly observed during transplantation of the right kidney. We present our experience with the elongation of short cadaveric right renal veins using the contiguous vena cava during cadaveric renal transplants.

Methods: We performed 34 kidney transplantations with a short right renal vein requiring elongation using the inferior vena cava, to make the venous anastomosis technically feasible. The elongated right renal vein was anastomosed end to side to the external iliac vein in 24 patients, to the common iliac vein in 8 patients and to the inferior vena cava in 2 patients. The right renal artery with an aortic patch was implanted end to side in 33 patients, and end to end without aortic patch to the internal iliac artery in one patient.

Results: In all cases, the vascular anastomoses were easily performed in the recipient and no thrombosis was observed.

Conclusion: Elongation of a short right renal vein with the inferior vena cava is a feasible mean to overcome technical problems that may compromise the results of cadaveric renal transplantation.
\end{abstract}

Key words: kidney transplantation; donors; cadaver; renal veins; inferior vena cava

Int Braz J Urol. 2005; 31: 519-25

\section{INTRODUCTION}

A short right renal vein (SRRV) is a frequent and well-known technical inconvenience, which is commonly observed during transplantation of the right kidney $(1,2)$. A short or damaged right renal vein can make renal transplantation very difficult (3-6). The right renal hilum has a single long artery and a short vein that causes difficulties while performing venous anastomosis either from living or cadaveric kidney transplantation, and especially when the right renal artery has an aortic path in the case of a cadaveric donor. It is more complicated and takes more time to perform the transplant especially in either deep iliac vessels, or in the obese or in both. Anastomosis of a SRRV to the common or external iliac vein has been reported to be associated with technical problems such as angulation or tension of the venous anastomosis, reduced mobility, limited placement and inspection of the graft for hemostasis, and possible kinking of the donor artery. One technical solution consists of a more extensive mobilization of the recipient's ves- 
sels, with the increased risk of lymphocele formation. A number of surgical approaches have been described to solve the problem of a SRRV (5).

Several techniques have been used to overcome this technical challenge such as renal vein extension using an autologous saphenous graft, bovine arterial heterograft or polytetrafluoroethylene (PTFE) vascular prostheses (5-8). A technique of extension of the right renal vein using the contiguous inferior vena cava was introduced to make vascular anastomosis feasible (1-11). Using this technique, a portion of the contiguous inferior vena cava is removed during organ harvesting to be used to extend very short right renal vein from cadaveric kidneys (1-11). The technique to obtain an appropriate length of the right renal vein using the vena cava is simple, physiological and feasible, and does not interfere with multiorgan procurement (3-11). In this study, we present our experience with the elongation of the SRRV using the contiguous vena cava.

\section{MATERIALS AND METHODS}

From 1991 to 1997 , we performed 243 consecutive cadaveric renal transplants in 243 patients at end-stage end chronic renal insufficiency. This protocol was approved by the local Ethics Commit- tee (\# 1111/02). The right kidney was used in 138 patients and from those, 34 kidneys had a very short renal vein requiring elongation using the vena cava to make the venous anastomosis technically feasible and to avoid kinking of renal arteries. From these 34 patients who received the kidney with a very short renal vein, the mean age was 39.4 years (17 - 56 years), and there were 19 males (55.9\%) and 15 females (44.11\%).

A technique used for procurement of cadaveric kidneys is removing the entire block. It was modified from Taylor et al. (9) and Chopin et al. (11). After removing the kidneys as an entire block, on a bench surgery, the left renal vein is divided at its origin on the vena cava and an entire segment of vena cava is left attached to the right renal vein. In 34 grafts with very short right renal vein, the segment of the vena cava below the ostium of the right renal vein was bent up to the level of the renal vein. The segment above the ostium and the excess of the bent-up lower segment were cut off. A running 5-0 monofilament polypropylene thread suture was used to close the upper defect in the vena cava. With this technique we obtained an extended renal vein. The lower segment of vena cava of the right renal vein was left as well as the length of the renal artery, and its excess was cut off. The aorta artery is split in the midline, leaving each half attached to the renal arteries of each kidney (Figures-1 to 3).

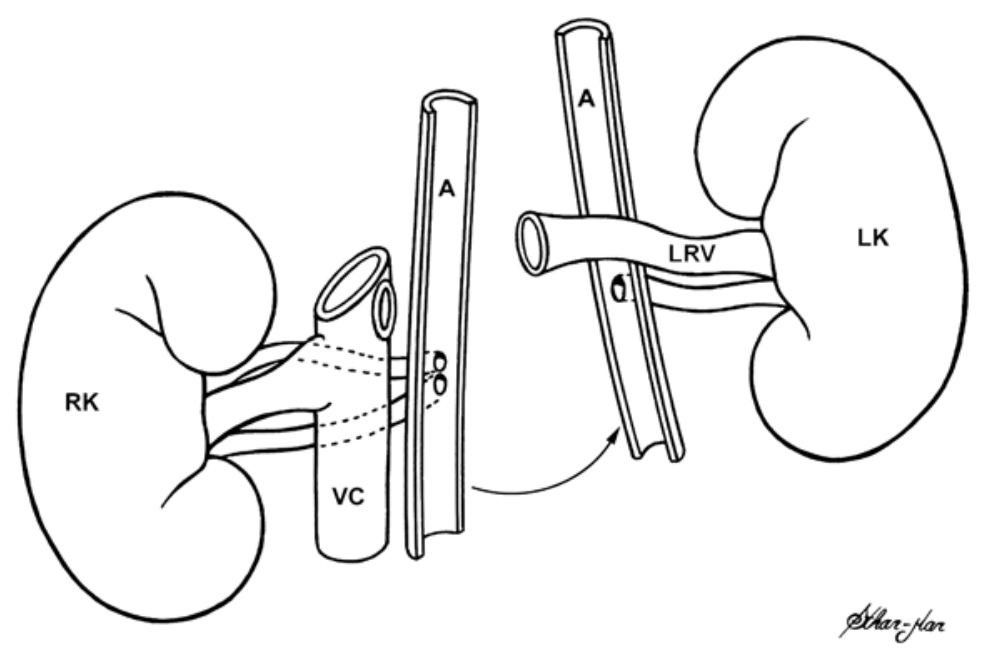

Figure 1 - Folding longitudinal split aorta and separation of cadaveric kidneys leaving vena cava intact attached to the right renal vein. $R K=$ right kidney, $L K=$ left kidney, $A=$ aorta, $V C=$ vena cava, $L R V=$ left renal vein. 

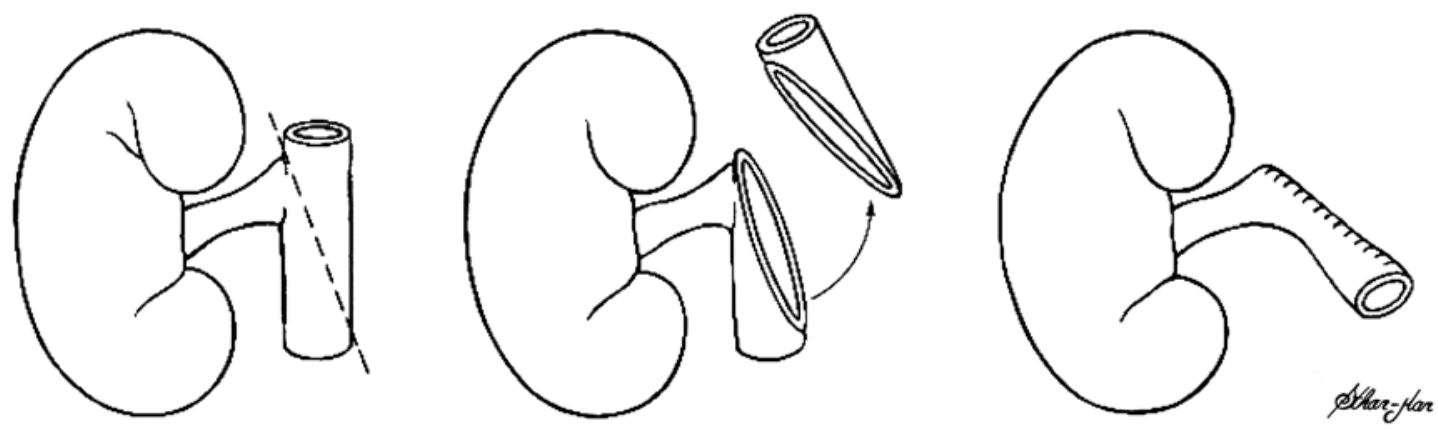

Figure 2 - Elongation of the right renal vein with segment of the vena cava.

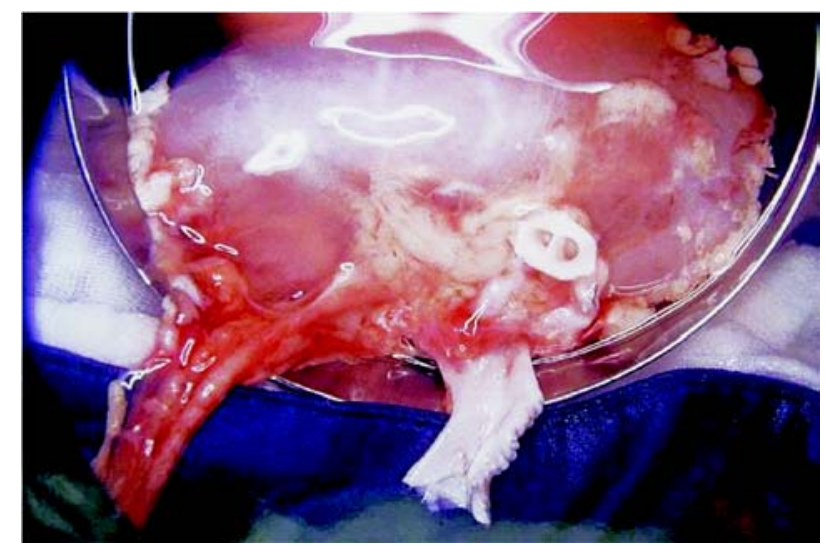

Figure 3-Bench surgery. Right vein elongated $(V)$, and patch of the aorta (A) attached to 2 renal arteries.

During renal transplantation an end-to-side anastomosis is performed between the ostium of the segment of vena cava and the recipient's external iliac vein or other vein (Figures-4 and 5).

In our study, we performed 34 transplants of the right kidney, 10 of which had 2 or more arteries attached to a single aortic patch, and 24 had a single artery. In 33 cases we used an aortic patch attached to the renal artery to perform the anastomosis.

From these 34 kidneys transplanted, the elongated right renal vein anastomosis was performed end to side to the external iliac vein in 24 cases, to the common iliac vein in 8 cases, and to the inferior vena cava in 2 cases. The right renal artery anastomosis was performed end to side using the aortic patch at- tached to the renal artery in 21 cases in the external iliac artery, in 10 cases in the common iliac artery, and in 2 cases in the aorta. End to end without aortic patch to the internal iliac artery was used in 1 case.

\section{RESULTS}

In all cases mentioned the vascular anastomoses were easily performed and no vascular throm-

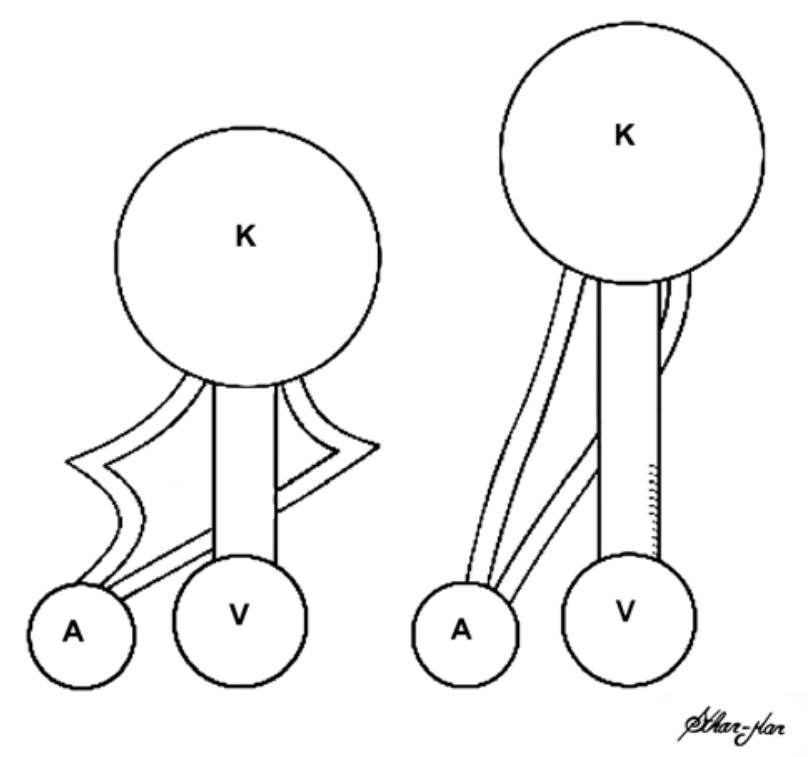

Figure 4 - Schematic drawings demonstrating that elongation of the right renal vein avoids kinking of the renal arteries. $A=$ iliac artery of the recipient, $V=$ iliac vein of the recipient, $K=$ kidney. 


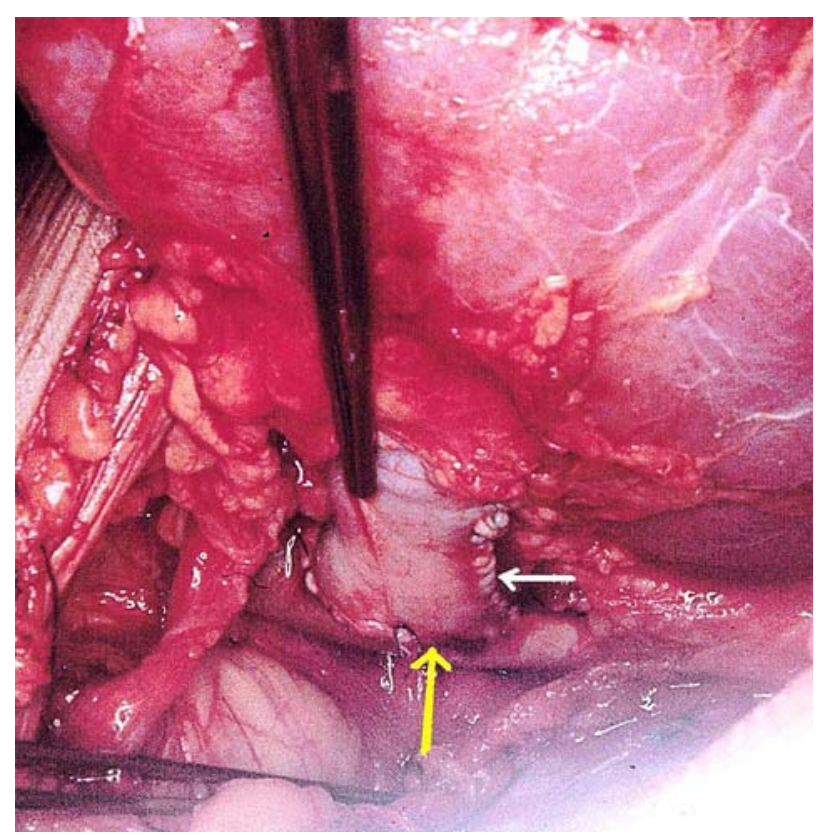

Figure 5 - Intraoperative picture of the right renal vein elongated (white arrow) and anastomosed end-to-side to the external iliac vein (yellow arrow).

bosis occurred. We have been following the progress of these 34 patients, which received cadaveric renal transplant with right renal vein extension, for more than 5 years. Eight patients lost their grafts from chronic rejection and 5 died from others medical complications (heart attack, malignant disease and infections) not related to the surgical approach.

\section{COMMENTS}

Technical complications associated with the venous anastomosis have been reported in 1 to $18 \%$ of all renal transplants $(2-5,10,11)$. These problems usually are related to trauma sustained during graft nephrectomy or transplantation. Difficulties are more likely to occur with the right kidney, since the right renal vein is shorter and anatomical variations are more frequent than on the left side $(5,12)$.

Janschek et al. (5) found the average length of the right renal vein to be almost one-half of the artery's length (A/V mean ratio 1.8) in 119 unselected formalin-preserved white adult cadavers, 58 were men and 61 women.
Short vessels can consume more time and extend the length of the warm ischemia during renal vessel anastomoses. In renal transplantation, when the vein is slightly longer than the corresponding artery, it allows easier venous and arterial anastomoses. Renal vein thrombosis is a serious complication leading to graft nephrectomy in many cases, despite medical or surgical therapy $(5,6)$. In addition to this risk, there is concern that continuous thrombosis to recipient vein may lead to pulmonary embolus $(5,10,11)$.

Attempts to join a renal vein of inadequate length to the iliac vein are likely to result in an anastomosis that is angulated or under tension. Extensive mobilization of the external iliac vein, to gain additional length, or dissection of the internal iliac vein to use end to end with the renal vein, may increase the likelihood of lymphocele formation because of unnecessary dissection and injury to lymphatics. These technical problems may lead to venous hemorrhage or thrombosis. Right renal vein elongation with the inferior vena cava seems to be a much better approach than venous saphenous autograft, spiral gonadal vein, bovine arterial heterograft and a vascular prosthesis, have been used for these surgical challenges $(5-8,13,14)$.

Dissection of the hilum of the donor kidney to lengthen the right renal vein is not recommended due the risk of parenchyma hemorrhage and injury of the blood supply of the pelvis and ureter and consequently can cause necrosis to both. Faulty surgical techniques maybe the cause for the majority of late ureteral stenosis, due to ureteral devascularization and ischemia, which could cause delayed ureteral fibrosis (3).

Right renal vein extension by transverse closure of the transected inferior vena cava solves the problem of the short right renal vein in cadaver kidney transplantation $(1,9,11)$.

Right renal vein extension is particularly important in kidneys with multiple vessels, in order to avoid lesions to these venous and arterial variations (11). Due to complicated embryological development, variations in renal vessels show extensive variability, from 12 to $25 \%$. These vessel anatomical variations are more frequent on the right side than on the left side $(3,8,12)$. Right renal vein extension allows 
an easier anastomosis and possibly better positioning of the kidney $(13,14)$. In our experience 10 of 34 right cadaveric kidneys had two or more arteries.

Benedetti et al. (1994) (13) showed in their study that the use of a vein extension had an impact on the outcome. Three hundred and five cadaver transplant recipients received a right kidney. Of these, 76 received a graft with vein extension. None of the 76 experienced technical vascular complications, however 5 of the $229(2.2 \%)$ without vein extension did. There was no difference in the survival of the kidney grafts with or without extension in follow up 1 to 2 years after transplantation. The authors concluded that there is no increased risk with the use of the vena cava extension and recommend that the donor team routinely provide the right kidney with the vena cava attached. This allows the recipient team to determine whether an extension is appropriate for the particular recipient. Elongation of the right renal vein with the vena cava is a feasible and physiological procedure and does not interfere with multiorgan procurement. No vascular complications were encountered. No other techniques were required. We recommend removal of the entire segment of vena cava during cadaveric kidney harvesting.

This technique eliminates the need to mobilize the recipient's vessels by a more extensive dissection, and the internal iliac vein division is not required. The kidney graft can easily be placed above the iliac vessels. This technique also preserves a patch of cadaveric aortic wall along with the right renal artery, thereby minimizing the risk of arterial graft kinking, renal transplant artery stenosis and thrombosis.

Performance of this technique depends upon the vena cava being left intact and attached to the right renal vein when the organs are separated (1,9,11,13-27). Multiple right renal veins can also be elongated with the inferior vena cava.

Despite, that this technique of the elongation of the right renal vein with the vena cava has been cited in literature for 30 years, even today it is neglected, which may jeopardize the viability of the kidney donated and the life quality of the recipient, as mentioned by others $(1,5,13-27)$. As also recommended by the U.S. Organ Procurement and Trans- plantation Network and the Scientific for Transplant Recipient and The Eurotransplant Manual (25-27).

When the recipient has extensive iliac and inferior cava venous disease, longer vein conduits can also be used to reach patent veins to drain the venous blood from the kidney graft, or perform orthotopic renal transplantation $(28,29)$. In some cases, it can be drained to the superior mesenteric (30), portal, splenic, subclavian veins or directly to the right atrium of the heart.

Some times the short right renal vein can be repaired or elongated with patch or flap of the inferior vena cava (22). Any others veins can be used as iliac or femoral cryopreserved allografts or from the same cadaver who was the donor of the kidney graft (31-34).

In conclusion, the elongation of the short right renal vein with the contiguous inferior vena cava is a feasible way to overcome technical problems that may jeopardize the results of cadaveric renal transplant. This procedure allows both kidneys to be taken with the full length of the renal vein and artery with an aortic cuff. The method is most useful when the right renal vein is extremely short or when the recipient has a large abdomen and a deep pelvis or both, also in case of severe disease of the iliac and vena cava veins.

\section{CONFLICT OF INTEREST}

None declared.

\section{REFERENCES}

1. Barry JM, Fuchs EF: Right renal vein extension in cadaver kidney transplantation. Arch Surg. 1978; 113: 300.

2. Novick AC, Straffon RA: Surgery of renal transplantation and complications. In: Novick AC (ed.), Vascular problems in urologic surgery. Philadelphia, Saunders. 1982; pp. 233-6.

3. Jordan ML, Cook GT, Cardella CJ: Ten years of experience with vascular complications in renal transplantation. J Urol. 1982; 128: 689-92.

4. Salaman JR, Clarke AG, Crosby DL: The management of kidney transplants damaged during their removal from the donor. Br J Urol. 1974; 46: 173-7. 
5. Janschek EC, Rothe AU, Holzenbein TJ, Langer F, Brugger PC, Pokorny H, et al.: Anatomic basis of right renal vein extension for cadaveric kidney transplantation. Urology. 2004; 63: 660-4.

6. Nerstrom B, Ladefoged J, Lund F: Vascular complications in 155 consecutive kidney transplantations. Scand J Urol Nephrol. 1972; 6 (Suppl. 15): 65-74.

7. Santiago-Delpin EA, Gonzalez Z: Successful renal vein reconstruction with a polytetrafluoroethylene vascular graft in kidney transplantation.. Am J Surg. 1985; 149: 310-1.

8. Spees EK Jr, Oakes DD, Light JA, Perloff LJ, Reckard CR: Successful renal vein reconstruction with bovine arterial heterografts. Ann Surg. 1977; 186: 749-51.

9. Taylor RJ, Hakala TR, Rosenthal JT: Use of vena cava to extend the right renal vein in cadaveric transplants. Surg Gynecol Obstet. 1985; 160: 279-80.

10. Szmidt J, Frunze S, Karolak M, Madej K, Sablinski T, Nazarewski S: Right renal vein extension technique in human kidney transplantation. Eur Urol. 1989; 16: 2046.

11. Chopin DK, Popov Z, Abbou CC, Auvert JM: Use of vena cava to obtain additional length for the right renal vein during transplantation of cadaveric kidneys. J Urol. 1989; 141: 1143-4.

12. Baptista-Silva JC, Verissimo MJ, Castro MJ, Camara AL, Pestana JO: Anatomical study of the renal veins observed during 342 living-donor nephrectomies. Sao Paulo Med J. 1997; 115: 1456-9.

13. Benedetti E, Fryer J, Matas AJ, Sutherland DE, Payne WD, Dunn DL, et al.: Kidney transplant outcome with and without right renal vein extension. Clin Transplant. 1994; 8: 416-7.

14. Nghiem DD: Spiral gonadal vein graft extension of right renal vein in living renal transplantation. J Urol. 1989; 142: 1525.

15. Benoit G, Hammoudi Y, Bellamy J, Bensadoun H, Charpentier B, Fries D, et al.: Surgery ex situ in kidney transplantation. Ann Urol (Paris). 1988; 22: 452-44.

16. Hammoudi Y, Benoit G, Bensadoun H, Charpentier B, Hiesse C, Fries D, et al.: Benefits of vena cava removal with the renal vein in cadaver kidney procurement: incidence of arterial complications. Transplant Proc. 1988; 20: 762.

17. Chin JL: Vena caval extension of right renal vein for cadaveric renal transplants. J Urol. 1988; 139: 552-3.

18. Tan LC, Rahman AU, Walters AM, Sadek SA: The inferior vena caval conduit - a neglected technique in transplantation of the right cadaveric kidney? Transpl Int. 2000; 13 (Suppl. 1): S60-3.
19. Nakatani T, Takemoto Y, Kim T, Uchida J, Han Y, Tsuchida K, et al.: Results of cadaver kidney transplantation with right renal vein extension. Urol Int. 2003; 70: 282-5.

20. Pampaloni F, Sanchez LJ, Bencini L, Taddei G: Caval extension of the right renal vein in cadaveric renal transplantation using the ETS 45 endoscopic stapler. Chir Ital. 2001; 53: 567-70.

21. Fabian MA, Herrin MK, Baxter J, Ackermann JR: Extension of the right renal vein in cadaveric renal transplants with use of the vena cava and the TA-30 V3 surgical stapler. Surg Gynecol Obstet. 1991; 173: 233-4.

22. Barry JM, Lemmers MJ: Patch and flap techniques to repair right renal vein defects caused by cadaver liver retrieval for transplantation. J Urol. 1995; 153: 18034.

23. Corry RJ, Kelley SE: Technic for lengthening the right renal vein of cadaver donor kidneys. Am J Surg. 1978; 135: 867.

24. Dalla Valle R, Mazzoni MP, Bignardi L, Busi N, Benozzi L, Gualtierotti M, et al.: Renal vein extension in right kidney transplantation. Transplant Proc. 2004; 36: 509-10.

25. 2001-Annual Report ofthe V.S. Organ Procurement and Transplantation Network and the Scientific Registry for Transplant Recipients: Transplant Data 1991-2000. http://www.optn.org

26. Separate procurement of the kidneys. In: Eurotransplant Manual. Leiden, Netherlands, Eutransplant Foundation. 1998; pp. 8-11.

27. European Association of Urology - Guidelines on renal transplantation - 2003 - http://www.uroweb.org/ files/uploaded_files/guidelines/renaltransplant.pdf.

28. Gibel LJ, Chakerian M, Harford A, Sterling W: Transplantation using inverted renal unit and donor vena cavailiac vein conduit to bypass recipient distal vena cava and iliac venous systems. J Urol. 1988; 140: 1480-1.

29. Mozes MF, Kjellstrand CM, Simmons RL, Najarian JS: Orthotopic renal homotransplantation in a patient with thrombosis of the inferior vena cava. Am J Surg. 1976; 131: 633-6.

30. Pillay SP, Lynch S, Strong RW, Ong TH, Kawamoto $\mathrm{S}$, Yamanaka J: Use of the donor iliac vein to replace the retrohepatic vena cava in pediatric reduced-size liver retransplantation. J Pediatr Surg. 1995; 30: 16989.

31. Aguirrezabalaga J, Novas S, Veiga F, Chantada V, Rey I, Gonzalez M, et al.: Renal transplantation with venous drainage through the superior mesenteric vein in cases 
of thrombosis of the inferior vena cava. Transplantation. 2002; 74: 413-5.

32. Launois B, Jamieson GG, Maddern G, Landen S, Campion JP, Coeurdacier P, et al.: Venous allografts: a useful alternative to venous autografts in digestive surgery. Aust N Z J Surg. 1995; 65: 579-81.

33. Goel MC, Flechner SM, El-Jack M, Veniro J, Kingman L, Modlin C, et al.: Salvage of compromised renal vessels in kidney transplantation using third-party cadaveric extenders: impact on posttransplant anti-HLA antibody formation. Transplantation. 2004; 77: 1899 902.

34. Adamec M, Janouoek L, Tooenovsky P, Lacha J: Renal transplantation combined with aortofemoral bypass using a fresh arterial allograft. Transpl Int. 2000;13 (Suppl. 1): S56-9.

Received: January 24, 2005

Accepted after revision: July 7, 2005

\author{
Correspondence address: \\ Dr. Jose C. Costa Baptista-Silva \\ Universidade Federal de São Paulo \\ Rua Borges Lagoa, 564 / 124 \\ 04038-000, São Paulo, SP, Brazil \\ Fax: + $55115574-5253$ \\ E-mail: jocabaptista@uol.com.br
}

\title{
EDITORIAL COMMENT
}

The study is very interesting and well conducted. The incidence of cases in which the renal vein needed to be elongated was $24.6 \%$, all of them with no complications. The elongation of a short right vein with the contiguous inferior vena cava is simple and safe. Many times the procurement team does not send the kidney with the entire segment of vena cava attached. In such cases, we need to consider other techniques of real vein elongation, with the portion of the cava attached instead of using any kind of graft or vascular prosthesis in view of the risks discussed by the authors. The use of a graft should be reserved to very special cases where a lesion of the renal vein has occurred. When no attached vena cava is available and the vein is too short we prefer to discard the aortic path instead of using a vein graft, even if a bench surgery is needed for an arterial reconstruction. The technique discussed by the authors is very interesting, safe and feasible and should be known by surgeons in charge of kidney transplants.

Dr. William Carlos Nahas Division of Urology, University of Sao Paulo Sao Paulo, SP, Brazil E-mail:wnahas@uol.com.br 